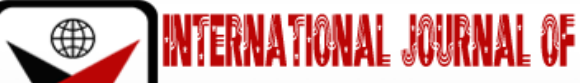

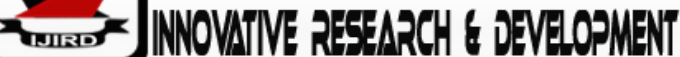

ISSN 2278-0211 (Online)

\section{Improving University Facilities \& Infrastructures: A Study of Mautech Yola}

\author{
Umbugala Muhammad Douglas \\ Seniour Lecturer, Department of Building, Baze University Abuja, Nigeria
}

\begin{abstract}
:
Global economy downturn requires proactive transformation in strategic management of our facilities to provide quality and better environment for learning. The revolution on integrated life-cycle management of facilities made Facilities management (FM) one of the fast-growing professions. This paper tends to address the back drop in design flexibility which has resounding effect on performance of facilities and largely the workplace. These affect greatly users essentially now that the world is opting for green initiatives, big data and IOT to gain with ease resource sustainability. This study provides options as prelude for improving existing facilities and future design in the campus. Questionnaires were sent out to different departments in the university with view to ascertain the state of facilities, its suitability and performance, effectiveness and flexibility in design visa viz the green concept. The approach uses simple statistical tool for the analysis.

The results of the survey had shown that a greater proportion of the sampled population opted for better facilities design to ensure compliance with the green concept. The workplaces require strategic reforms in order to foster better performance and value. This study introduced a paradigm shift to ensure more productivity and a better centre for academic excellence in the institution. This has breached the gap in theory by integrating multiple facets of performance measures as tool to facilitate effective and sustainable designs for optimal delivery in our academic pursuits.
\end{abstract}

Keywords: Facilities management, strategy, design, flexibility, sustainability, performance

\section{Background}

The global change had forced both government parastatals and private industries to substantially adapt to sustain quality in workplaces; this indeed made the old slogan of business as usual irrelevant and unacceptable. To this regard's buildings are designed to give shelter that are in balance with ecosystem thus providing environmental friendly and driving sustainable quality of life. The challenges our planet faces are enormous, particularly climate change, sustainable economic and infrastructure development are global in nature and so require global solutions [51]. Strategic flexibility is thus key and critical for enabling rapid adaptation to change. More attention should be paid during design to add character and identity to the environment. The design initiatives should provide for integration of the financial, technical and strategic planning requirements. This will promote positive work ethics, sense of belonging and better participation by all The paper is a call towards design adequacy, relevance of Facilities management and conscious towards improving universities facilities to deliver the future. Development in many fronts, require transformation in strategies, in order to meet flexibility in the workers and students' academic pursuits. Citizen expectations are changing, which demand faster and more personalized services, these indeed require the university infrastructures to meet with the changing dynamics. Sustainable university campuses are livable environment that meet the diverse needs of the community both now and the future. It is well designed, safe and secured with flexibility to depict quality environment for maximum output in research and development. Many universities are driving towards the path of innovation, moving from discrete and disparate system to resource collaboration (big data and IOT) [54]. Managing facilities performance to corporate objectives and its continual improvement remain a challenge. Building a culture of performance excellence requires provision of strategy and matrix that will empower employees and students' to the many facets and outlets of creativity and innovations [32] which indeed will meet this era of choice and flexibility. Focusing on ecological future is only part of the story; Sustainability entails responsiveness and complimentary organization strategy that can meet change and uncertainty $(6 ; 12]$. It could be defined as development that meets the future without compromising the present dynamics. This entails providing flexible working environment, a cause and effect relations to proactively response to issues, thereby magnifying success and value to the academic circle. The future of educational growth depends on research and innovation; however this goal cannot be achieved if the right measures are not in place. This study extends the theoretical debate on harmonizing strategy, design and operational performance measures in a workplace. 


\section{Towards a Sustainable University}

How does a city or university thrive in the 21st century? Whenever a city or university walked away from investing on infrastructure and people then it ceases to be competitive. Infrastructure development as documented in the socio-economic literature is a significant factor driving economic growth in any nation. Infrastructures considerably affect growth; quality reduces economic disparity and poverty level. Direct investment on infrastructure is capable of promoting positive externalities in terms of making available production facilities and at the same time lowers costs associated with trade transactions and generate employment opportunities for the people. Conversely, lack of infrastructure constitutes a serious threat to development, sustainable growth and worsens greatly the poverty level. The city tends to fall apart as there will be unemployment, crime will be skyrocketed. Sustainability Thus, could be defined and understood as the increase in social and economic capital, in a way that the consumption of natural resources is controlled.

Designing sustainable university with high density will requires adopting a flexible environmental design strategy. These involve computational fluid dynamic studies to careful orient and position the buildings to improve natural lighting and ventilation while reducing thermal heat gain in Jimeta Yola with hot and temperate climate. Departments are encouraged to plant trees for a balanced ecosystem. Auto desk's building information modeling (BIM) technology can be used to assist with the design of green buildings. This involves cloud based whole-building energy analyses which enable the optimization of energy efficiency and work towards carbon neutrality. The performance of existing and new building designs can be improved through simulation and building analysis including water and carbon emission analysis. With such initiatives the quest towards zero energy consumption buildings in the campus will be a reality. The search also involves developing intelligent system that will provide real time situation and information as well as models to monitor impact of planning and sustainability efforts. These require exploring solution that will make the university campus smarter, more connected, live-able, inclusive and environmentally friendly. This indeed will make Mautech a 'living lab' where companies and researchers can be more connected, collaborate, create, demonstrate and commercialize innovative urban solutions in live mix-use environment.

The global financial meltdown is a cause for concern. Ethics and moral conduct continue to decline, to be competitive, the institution has to adapt to inspire workers and student to the new level and optimal performance. Benchmarking can be a catalyst assisting organization and institution to be more focused, competitive and productive thus improving the revenue drive of the institution and productivity curve. The objective is to improve performance and gain strategy advantage that will have a resounding effect on the graduates. Endeavors to find solution to complex social, economic and environmental challenges requires resource collaborations, automation, big data and IOT, and relatively few have the internal capacity to deliver such. Facilities management is a business enabler and capable of contributing towards the university success with the right strategy in place can generates greatest impact on academic excellence and productivity. The increasing importance of knowledge both for competitiveness and to address socio economic challenges require frantic effort with the strategic design of the facilities to meet 21st century performance. As technology development continues to expand so will the possibilities magnified bringing more flexibility, efficiency and excellence to delivery.

\section{Mautech and the Green Initiatives}

Management challenge, the growth in volume is largely attributed to the nonchalant attitude towards the practice, which led to ineffectiveness, partly due to lack of supervision, monitoring of work execution. The school management will continue to experiences increasingly complex set of building decay if these vices are left unattended. Evaluation of existing and new design of facilities should be carried out with more flexibility to ensure its effectiveness and sustainability. Operational excellence requires project delivery that is safe, reliable, efficient and environmentally friendly at a healthy cost. This is providing a work class opportunity for learning and workforce culture with a mindset that depicts change. Management insights through committed leadership should provide framework that integrates logical activities and operations with deeper insight into design considerations for better and quality delivering in academic standard. Sustainable initiatives encourage approaches that moves away from fragmentation to bring integrity in students, magnifying values and growth that bears on learning and innovations. Mautech vision of becoming a world class university in science and technology cannot be achieved without an enabling environment and coherent structures to support the students adequately. The management should establish work class expectations, vision and strategic objectives with tenets of operational excellence. The green concept permutation offers an integrated vistas and visual identities creating multifunctional objectives that meet thermal performance, energy conservation and indeed 21st century performance and expectations. This environment will play a profound role and influence on the academic excellence in the institution with very tense and harsh weather.

Research studies had attributed the decline in academic excellence to lack of adaption to best practices; this inexorable fact of life obviously had changed the dynamics of many learning hubs. There is worldwide trend towards green concept because it offers potential for value enhancement and sustainability. However, the focus on tactical issue and strategic planning is given inadequate consideration by many universities consequently under performance and obvious resource wastage is imminent $[14 ; 6 ; 52]$.

Sustainable service delivery requires viable strategies that focus towards green initiatives, human capital; these consequently triggered the need for shift in performance measurement and management $[38 ; 29,56]$.

\subsection{Moving With the Changing Dynamics}

As the drive towards more academic excellence heightens it is more evident to reflect on the intertwined relationship between educational goals such as cost cutting to rising learning and education value. Green concept is an 
emerging practice that requires proactively leaps over the traditional limited functions and strategies paving way to sustainable facilities that will yield more dividends. Communities and high school must embrace the reality of smart grids, emerging storage technologies, and renewable energy generation. Social and economic forces are coming together as the nation ponders over its sustainable future. Now, with global warming and climate change having an impact on everyone's daily lives, can anyone wait any longer? On an economic front, the world is battling the most severe economic downturn since the Great Depression of the 1930s.To achieve sustainable success requires relevant performance measure to communicate insights and value to all. Renewable power generation is the core need for this generation. Again, will America fall further behind? That is a distinct possibility, as the European Union, Japan, and now China becoming ever more aggressive in renewable energy generation and technologies. The future needs collaboration and synergy to ensure performance and sustainable delivery of goals. There is the dire need for thermal comfort, serene and sustainable environment for learning to raise the bar in the academic excellence. The world is undergoing transformation and every sector of the economy including education is not left out if it must remain relevance. Information and communication technology are introduced in education sector to increase effectiveness and efficiency. It is more than a trend rather the wave of the future to ensure quality and performance are optimized.

\section{Methodology}

Driven by the pathetic situation and the guest for excellence, an intensive literature search was carried out. Over 100 Questionnaires were distributed physically to the university community to ensure an inclusive research effort that will meet a warren audience. Building on prior simplification and standardization a 5-point Likert scale designed which was focused on effectiveness and efficiency as this is central to higher university education. 101 questionnaires were returned however only 96 were used for this research study. The design initiatives is to facilitate and accelerate transition to climate resilient that meet unique sense and campus identity.

\section{Results and Discussions}

\subsection{Table 1 below Show Case Processing Summary}

\begin{tabular}{|c|c|c|c|}
\hline & N & \multicolumn{2}{|c|}{ \% } \\
\hline Cases & Valid & $\mathbf{9 6}$ & $\mathbf{9 7}$ \\
\hline & Excluded(a) & 3 & 3 \\
\hline & Total & 99 & 100 \\
\hline
\end{tabular}

Table 1: Processing Summary

a. Listwise Deletion Based on All Variables in the Procedure

\subsection{Table 2 Shows the Reliability Statistics}

\begin{tabular}{|c|c|c|}
\hline Cronbach's Alpha & $\begin{array}{c}\text { Cronbach's Alpha Based on } \\
\text { Standardized Items }\end{array}$ & N of Items \\
\hline .629 & .695 & 7 \\
\hline
\end{tabular}

Table 2: Reliability Statistics

The Cronbach's Alpha based on the standardized items has a value 0.695 denoting the model fit. This entails that the structural design of the questionnaire met certain degree of credence.

\subsection{Item Statistics}

\begin{tabular}{|c|c|c|c|}
\hline & Mean & Std. Deviation & $\mathbf{N}$ \\
\hline $\mathrm{X} 1$ & 3.0738 & 1.40856 & 96 \\
\hline $\mathrm{X} 2$ & 3.1053 & 1.16505 & 96 \\
\hline $\mathrm{X} 3$ & 3.8420 & 1.02921 & 96 \\
\hline $\mathrm{X} 4$ & 3.3051 & 1.26552 & 96 \\
\hline $\mathrm{X} 5$ & 3.2739 & 1.02024 & 96 \\
\hline $\mathrm{X} 6$ & 2.6104 & 1.18139 & 96 \\
\hline $\mathrm{X} 7$ & 3.2017 & .62543 & 96 \\
\hline
\end{tabular}

Table 3: Shows Analysis of Variance (ANOVA) 
5.4. Table 4: ANOVA with Friedman's Test

\begin{tabular}{|c|c|c|c|c|c|c|}
\hline & $\begin{array}{c}\text { Sum of } \\
\text { Squares }\end{array}$ & df & Mean Square & $\begin{array}{c}\text { Friedman's Chi- } \\
\text { Square }\end{array}$ & \multicolumn{2}{|c|}{ Sig } \\
\hline Between People & 260.126 & 95 & 2.738 & & & \\
\hline Within People & Between Items & $76.921(\mathrm{a})$ & 6 & 12.820 & 67.577 & .000 \\
\hline & Residual & 578.720 & 570 & 1.015 & & \\
\hline Total & 915.767 & 671 & 1.365 & & & \\
\hline
\end{tabular}

Table 4: ANOVA with Friedman's Test

Kendall's Coefficient of Concordance $W=.084$.

Grand Mean $=3.2017$

The result had shown significance at 0.00 signifying $90 \%$ confidence levels with $\mathrm{F}$ value at 67.577 , this indeed had shown the relevance of the design and the model fit.

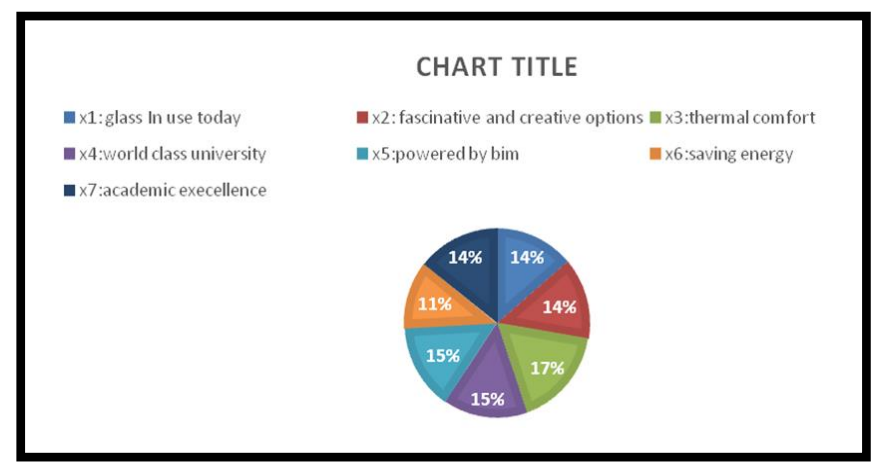

Figure 1

Many institutions and workplaces are driving towards the path of innovations moving from discrete and disparate systems to smart concept [54]. The creation of facilities and infrastructures which support an institution core activity is an overriding objective. Delivery effective services requires visible reforms to provide magnified and optimal pathways, which entail clear strategic leadership commitments, process design, technology and people [53].

\section{Summary}

Innovation should be key to our approach to the university vision. New challenges and opportunities demand bold and ambitious response to issues on academic leadership and excellence. $17 \%$ of the sampled population opted for thermal comfort while $15 \%$ want the university to work towards being a world class institution and also powered by building information modeling. $14 \%$ of the sampled population want a fascinating design option, glassy to pave way for academic excellence. The low marks in $11 \%$ reflected the general low level of awareness on green concept and thus the university consciousness towards sustainability.

\section{Conclusion}

The unique set of constituents outlined by the sampled population offered an indication of strategic and facilities gap realized by the study. The analysis had shown that greater proportion of the sampled population opted for better facilities infrastructure, however this vision was not supported adequately with coherent structure. Design flexibility has resounding consequence on performance of facilities and largely the workplace. These affect greatly users essentially now that the world is opting for green initiatives, big data and IOT to gain with ease resource performance and sustainability. This result had indicated that the university infrastructures lacked the capacity to support effectively its mission and vision 'being a world class university'. Smart and Sustainable university education is an overwhelming ambition that is global and collaborative undertaking to optimizing operational performance. This indeed, is more than a trend, rather waves and effort towards delivery the future. Today savvy consumers are looking for proficiency and excellence; their perception of value is tied to quality, the degree of excellence or empowerment by the university that will ensure better delivery and more productivity. Green and smart concept are recommended for adoption to improve the school facilities, sustain performance and excellence that will move productivity curve beyond expectations. This indeed the reality and the new norms that will guarantee quality and performance at the optimal. Building a culture of performance excellence requires strategy change that is smart to guarantee better and desires value. The emerging academic institution to be successfully needs strategy that is flexible, integrating and sustainable to pool facilities resources together as basis for high 
performance and added value. The study extends the theoretical debate on harmonizing strategy and operational performance measures of an institution, as this era is moving into a conceptual age where competence will be achieved only by provision of strategy that seeks to guarantee expectations of all.

\section{References}

i. Amarantunga, D., and Baldry, D. (2003). A conceptual framework to measure facilities management performance. 21(2), 171-189

ii. Alexander, K., and Brown, M. (2006). Community- based Facilities Management. Facilities, 24(7/8), 250-268

iii. Belcher, R. G. (1997). COBRA '97' 'Corporate Objectives, Facilities Management and Use'. Royal Institute of Chartered Surveyors

iv. Biech, E. (2004). Pfeiffer essential resources for training and HR professionals. business/management (2004 Pfeiffer annual Consulting), 205-215

v. Boudreau, J. W., and Ramstad, P. M. (2007). Beyond HR 'The New Science of Human Capital' (2nd impression and printed in USA). Boston, Massachusetts: Harvard Business School Press

vi. Bovee, L. C., and Thill, J. V. (2006). Business in Action (3rd ed.). Upper Saddle River New Jersey, U.S.A: Pearson Education Inc.

vii. Buam, S., V, J., and S, B. (2005). Multiple Intelligence in the Elementary Class 'A Teacher's Toolkit'. U.S.A, Columbia: Teachers college Press Columbia University.

viii. Dixon, R. J., Alfred, J. N., and Thomas, E. V. (1990). The New Performance Challenge 'measuring a world class operation. U.S.A.: The Dow Jones Irwin/Apics series in production management.

ix. Dubem, I. K., Stephen, 0. 0., and Anthony, O. U. (2014) " An investigation on policy direction and drivers for sustainable facilities management practice in Nigeria" Facilities Management, 12 (3), 303-322.

X. Duffy, A. H. B., and O'Donnell, F. J. (2005). Design Performance: British Library Cataloguing in Publication Data.

xi. Best, R., C, L., and Valence, G. D. (2003). Workplace Strategies 'facilities management'. Oxford, U.K: Butterworth Heinemann Elsevier Science Ltd.

xii. Amaratunga, D., Haigh, R., Sarshar, M., and Baldry, D. (2002). Assessment of Facilities Management Process Capability 'A NHS Facilities case study'. International Journal of Health Care Quality Assurance, 15(6), 277-288

xiii. Amaratunga, D., Baldry, D., and Sarshar, M. (2000). Assessment of Facilities Management Performance- what next? Facilities, 18(1/2), 66-75

xiv. Ernst and Young. (2002). Strategic Programme management 'thought to finish'. Corporate real estate London, $1-2$.

xv. Fleming, D. (2004). Facilities Management 'A behavioral approach'. Facilities, 22(1/2), 35-43

xvi. Friedman, D. (2006). Pfeiffer essential resources for training / HR professionals "Demystifying outsourcing" (2nd, 2006 by John Willey and sons Inc ed.): Pfeiffer an imprint of Wiley

xvii. Gallos, J. V. (2006). Organization Development (2ND ed.): Jossy-Bass and Business and Management Series.

xviii. Gareis, R., and Cleland, D. I. (2006). Global project management handbook (second ed.). New York London Singapore Toronto: McGraw Hill Companies, Inc.

xix. Gerald, G. C., Ceccherelli, L., and (2004). User Centric Facilities Management 'A decentralized approach'. Facilities, 12(11/12), 296-302

xx. Gilleard, J. D., and Granath, J. A. (2007). Usability in the Workplace 'Case study of Pamela Youde Eastern Hospital, Hong Kong'. Paper presented at the CIB World Building conference.

xxi. Gottschalk, P. (2006). e-Busines Strategy 'Sourcing and Governance'. Hershey London, Melbourne Singapore: Idea Group Inc.

xxii. H.C.Tsang, A., Andrew K.S. Jardine, and Kolodny, H. (1999). Measuring maintenance performance ' A holistic approach'. International journal of operation \&production mana, 19(7), 691-715

xxiii. Hassanain, M. A., Froese, T. M., and Vanier, D. J. (2003). Framework Model for Asset Maintenance Management. Performance of Constructed Facilities, 17(1), 51-64

xxiv. Hui, E. Y. Y., and Tsang, A. H. C. (2004). Sourcing Strategies 'facilities management'. Quality in Maintenance, $10(2), 85-92$

xxv. Jayyousi, K. W. (2001). Development and implementation of a service quality rating system for facilities management for urban schools. PHD Thesis. Wayne state university, Detriot Michigan.

xxvi. Jensen, P. A. (2010) 'The facilities Management Value Map: a conceptual framework' Facilities, 28 (3/4), 175188.

xxvii. Jones, O. (2000). Facility Management 'Future Opportunities, Scope and Impact'. Facilities, 18(3/4), 133-137

xxviii. Kearns, P. (Ed.). (2000). Measuring and Managing employee performance (2nd British Library Catalogue ed.). Great Britain: Prentice Hall.

xxix. Keith, A. (2007). A strategy for facilities management. National Asset and Facilities Management Convention, 13-Putra World Trade Centre Kuala Lumpur.

xxx. Kelly, J., Hunter, K., Geoffrey, S., and Ann, Y. (2005). Briefing from a facilities management perspective. Facilities, 23(7/8), 356-367

xxxi. Kincaid, D. (1994). Integrated Facility Management. Facilities, 12(8), 20-23

xxxii. Kumar, A. and Sushi, S. (2013). "Modelling strategic performance factors for effective strategy execution" I Productivity and performance management, 62 (6), 554-582 
xxxiii. Kwok, C. M. J., and Warren, A. W. L. (2005). Optimization of performance in facilities management. Pacific Rim Real Estate Society Conference, 1-15

xxxiv. Neely, A. (1999). The Performance Measurement Revolution 'Why now \& what next'. Operation \& production management, 19(2), 205-228

xxxv. 35. Myeda, N. E., Kamaruzzaman, S. N, and Pitt, M (2011) "Measuring the performance of office building maintenance management in Malaysia" Facilities Management, 9 (3), 181-199.

xxxvi. Oakland, J. S. (2003). Total Quality Management 'text with cases' (3rd by Elsevier imprints Inc ed.). Amsterdam London New York: Butterworth Heinemann.

xxxvii. Omirin, M. M. (2005). Principles of Facilities Management. Facilities Management for Sustainable Building Performance, 1, 1-10

xxxviii. Ployhart E. Robert, Benjamin Schneider, and Schmitt, N. (2006). Staffing Organization 'contemporary practice \& theory': 2006 by Lawrence Erlbaum Associates, Inc.

xxxix. Price, I. (2002). Can Facilities Management Evolve? Facilities Management, 1(1), 56

xl. Roopchan, L., and Pickett., R. M. (2002). Best Practice Implementation. Proquest Science, 133(11), 24

xli. Roulac, S., and Heaney, G. (2005). Corporate Strategic Decision Making. Property Investment and Finance, 23(4), 364-378

xlii. S. Kaya, Christopher, A. H., Kirsten, A., B. Graham, and A. Keith. (2004). Raising Facilities Management's profile in organizations: Facilities Management, 3(1).65-87

xliii. Schermerhorn, J. R. (2007). Exploring Management in Modules: John and Wiley and Sons Inc.

xliv. Shaalan, T. M. (2006). Optimizing the global performance of BOSC. University of central Florida, Orlando, Florida.

xlv. Stenzel, C., and Stenzel, J. (2003). From Cost to Performance Management: John Wiley and Sons Inc. published in Canada.

xlvi. Tay, L., and Ooi, J. T. L. (2001). Facilities Management 'a jack of all trades?' Facilities, 19(10), 357-362

xlvii. Then, D. S. (1999). An integrated resource management view of facilities management. Facilities Management, $17(12 / 13), 462-469$

xlviii. Tomas, M., Andreas, V. W., and Emiel, W. (2004). Assessing the innovative ability of FM teams. Facilities, $22(11 / 12), 290-295$

xlix. Tucker, M., and Smith, A. (2007). User Perception in Workplace. Facilities, 26(5/6), 196-212

l. Tucker, M., and Pitt, M. (2010) "Improving service provision through better management and measurement of customer satisfaction in facilities management" Corporate Real Estate, 12 (4), 220-233/

li. Tony Arnel (2012) (world green building concept 'green building index Malaysia

lii. Umbugala, M. D., Hishamuddin, B. M. A., and Abdul Hamid, B. M. I. (2009). Timeless Practice 'the outsourcing focus'. Refereed Paper at the Pacific Rim Real Estate Society (PRRES) Conference.

liii. Umbugala Muhammad Douglas, Hishamuddin Bin Mohd Ali. Delivery an Effective Workplace: A Search into Malaysian Outsourcing

liv. Firms. Science Journal of Business and Management. Vol. 7, No. 2, 2019, pp. 51-58. doi: 10.11648/j.sjbm.20190702.12

lv. Umbugala Muhammad Douglas, Bala Muhammad. Building collapse 'A review \& delivery of the future using Big Data and IOT’ Innovative research \& Development Vol 9/8 Pp 167-173

lvi. Werner, J. M., and DeSimone, R. L. (2006). Human Resource Development (2 ed.). Printed in USA: Thompson South-Western Corporation.

lvii. Xianhai, M., and Micheal, M. (2011) "Performance Measurement models in facility management: a comparative study" Facilities, 29 11/12, 472-484.

lviii. Yiannis, K., Paul, H., Robert, E. M. (2012) 'Pursuing 'flexible commitment' as strategic ambidexterity; An empirical justification in high technology firms" European journal of marketing, 46(10) 1389-1417. 